\title{
Association of Aortic Pulse Wave Velocity with the Severity of Coronary Artery Disease in Patients with Non-ST-Segment Elevation Myocardial Infarction
}

\author{
Pinaki Ranjan Das¹, Muhammed Aminur Razzaque ${ }^{2}$, Rashid Ahmed ${ }^{3}$, Shafiqul Islam², Rabindra Nath Barman, \\ Ashiqur Rahman Khan ${ }^{5}$, Md. Mamunuzzaman ${ }^{6}$, A. B. M. Nizam Uddin , Abdul Kader Akanda ${ }^{8}$, M. G. Azam
}

\begin{abstract}
:
Background: Noninvasive assessment of arterial stiffness with aortic pulse wave velocity (PWV) may serve as a useful adjunct to the cardiovascular risk stratification and risk management. The aim of this study was to evaluate the association between aortic PWV and severity of coronary artery disease (CAD) in patients with non-STsegment elevation myocardial infarction (NSTEMI).

Methods: This cross sectional analytical study was conducted over 100 NSTEMI patients who were purposively selected and agreed to do coronary angiogram during index hospital admission. PWV was assessed noninvasively using the SphygmoCor ${ }^{\circledR}$ system on the day before coronary angiogram (CAG). Study subjects were divided into two groups on the basis of PWV. In group I: PWV was $\leq 10 \mathrm{~m} / \mathrm{sec}$ and in group II: PWV was $>10 \mathrm{~m} / \mathrm{sec}$. Fifty patients in each group. Angiographic severity of CAD was assessed by vessel score, Friesinger score and Leaman score.

Results: Vessel score 2 and 3 were significantly $(p<0.05)$ higher in group II and vessel score 0 and 1 were significantly $(p<0.05)$ higher in group I. The mean PWV in the group with normal angiographic results was $8.21 \pm 1.8$
\end{abstract}

$\mathrm{m} / \mathrm{sec}$, and in patients with single-vessel disease it was $9.88 \pm 2.02 \mathrm{~m} / \mathrm{sec}$. In those with double and triple vessel disease the mean PWV was found $11.95 \pm 2.61 \mathrm{~m} / \mathrm{sec}$ and $14.37 \pm 2.96 \mathrm{~m} / \mathrm{sec}$ respectively. There was a significant difference of the mean value of PWV among the vessel involvement group $(p=0.001)$. Normal and low Friesinger score were significantly $(p<0.05)$ higher in group I patients. Intermediate and high Friesinger score were significantly $(p<0.05)$ higher in group II patients. Increased PWV was significantly associated with the presence and severity of CAD in NSTEMI. This association showed a positive linear relation between the values of PWV and vessel score $(r=0.65, p=0.01)$, Friesinger score $(r=0.61, p=0.01)$, and Leaman score $(r=0.36, p=0.01)$.

Conclusion: From this study it may be stated that arterial stiffness, as measured by the aortic PWV, is an independent predictor of the presence and extent of CAD. Measurements of aortic PWV in NSTEMI can detect high risk patients requiring an early invasive strategy over a delayed invasive strategy.

Keywords: Pulse wave velocity (PWV), NSTEMI, Coronary artery disease (CAD)

(Bangladesh Heart Journal 2021; 36(1): 38-46)

1. Assistant Professor, Department of Cardiology, National Institute of Cardiovascular Diseases, Dhaka, Bangladesh

2. Assistant Professor of Cardiology, National Institute of Cardiovascular Diseases, Dhaka, Bangladesh

3. Assistant Professor of Cardiology, Colonel Malek Medical College, Manikgang, Bangladesh

4. Associate Professor of Cardiology, Rangpur Medical College, Rangpur, Bangladesh

5. Assistant Professor of Medicine, Cumilla Medical College, Cumilla, Bangladesh

6. Assistant Professor of Cardiology, Shaheed M. Monsur Ali Medical College, Sirajgang, Bangladesh

7. Assistant Professor of Cardiology, Sylhet MAG Osmani Medical College, Sylhet, Bangladesh

8. Professor of Cardiology, Sir Salimullah Medical College, Dhaka, Bangladesh

9. Professor of Cardiology, National Institute of Cardiovascular Diseases, Dhaka, Bangladesh

Address of Correspondence: Pinaki Ranjan Das, Assistant Professor, Dept. of Cardiology, National Institute of Cardiovascular Diseases, Dhaka, Bangladesh. Tel: +8801720053429, E-mail: pinakipbt@gmail.com

DOI: https://doi.org/10.3329/bhj.v36i1.55516

Copyright $\odot 2017$ Bangladesh Cardiac Society. Published by Bangladesh Cardiac Society. This is an Open Access articles published under the Creative Commons Attribution-NonCommercial 4.0 International License (CC BY-NC). This license permits use, distribution and reproduction in any medium, provided the original work is properly cited and is not used for commercial purposes. 


\section{Introduction:}

Increased arterial stiffness has been associated with increased risk of $\mathrm{Ml}$, stroke, congestive heart failure and overall mortality. ${ }^{1}$ Increased arterial stiffness correlates with coronary risk factors as well as measures of arterial stiffness correlate with the presence of angiographic CAD. ${ }^{2}$ Noninvasive assessment of arterial stiffness may serve as a useful adjunct to the cardiovascular risk stratification and risk management. ${ }^{3}$

Among the different noninvasive methods used to assess arterial stiffness the carotid femoral pulse wave velocity (PWV) has emerged as a gold standard due to its accuracy, reproducibility, relative easy measurement, and low costs. ${ }^{4}$ PWV increases as arterial stiffness rises and it is an independent predictor of cardiovascular event over and above the existing risk factors. ${ }^{5}$ Studies concerning pulse wave velocity and severity of coronary artery disease in non-ST-segment elevation myocardial infarction (NSTEMI) have been carried out predominantly in the developed countries, but there was no adequate data from Bangladesh addressing PWV as an independent risk assessment tool for predicting the severity of CAD.

Because a noninvasive approach clearly would be of value for the examination of a large population at risk, this noninvasive tool for the prediction of severity and extent of CAD in NSTEMI patients, this study was designed to demonstrate in detail the association between aortic pulse wave velocity and severity of CAD.

\section{Materials and methods:}

This cross sectional analytical study was conducted in the National Institute of Cardiovascular Diseases (NICVD), Dhaka from March 2013 to November 2013. Patients were purposively selected with NSTEMI and agreed to do coronary angiography (CAG) during index hospital admission. Total 100 patients were included in the study. Assessment of PWV was performed noninvasively with the commercially available SphygmoCor® system (SphygmoCor Vx pulse wave velocity system Model SCOR-Mx DCN: $100521 \mathrm{P} / \mathrm{N}: 1-$ 00418, Rev: 9.0/0-0m, SphygmoCor Software Version: 8, AtCor Medical Pty Ltd. Sydney, Australia) using applanation tonometry with a high-fidelity micro manometer (Millar Instruments). Patients with STEMI and UA, valvular heart disease, congenital heart disease, cardiomyopathy, myocarditis or pericarditis, major non cardiovascular disorder such as severe renal impairment, patients with moderate to severe left ventricular systolic dysfunction, and patients known to have clinically evident peripheral artery disease (PAD), coarctation of aorta, aortic aneurysm, and aortic dissection were excluded from the study. Study protocol was approved by the Ethical Review Committee of NICVD.

\section{Noninvasive assessment of pulse wave velocity:}

The SphygmoCor ${ }^{\circledR}$ Vx pulse wave velocity system were used for the study to measure the velocity of ECG-gated blood pressure waveform between two superficial artery sites (carotid and femoral) using applanation tonometry. For the study the distance from the suprasternal notch to the distal measurement site (femoral), as well as, to the proximal measurement site (carotid) were measured. Subtracting the proximal measurement distance from the distal measurement distance determined the PWV distance. The mean time difference between R-wave of the QRS complex of ECG and the pressure wave on a beat by beat basis was calculated by SphygmoCor Vx Software process from each set of pressure pulse and ECG waveform data. The PWV was calculated using the mean time difference and the arterial path length between two recording sites. All PWV measurements were taken in a quiet, temperature-controlled room $\left(22 \pm 1^{\circ} \mathrm{C}\right)$ after a brief period (at least 5 minutes) of rest, most often on the day before cardiac catheterization by a doctor not involved in performance or interpretation of the angiograms.

\section{Assessment of angiographic pattern and severity of CAD:}

Coronary angiography was done during same hospital stay. Interpretation of coronary angiogram was done by visual estimation by two cardiologists to assess the severity of CAD. Severity of coronary stenosis was graded according to the number of major epicardial vessel with significant stenosis (vessel score), Friesinger score and Leaman score.

\section{A. Vessel score: ${ }^{6}$}

This is the number of vessels with a significant stenosis (for left main coronary artery $50 \%$ or greater and for others $70 \%$ or greater reduction in luminal diameter). Score ranged from 0 to 3 , depending on the number of vessel involved.

Score $0=$ no vessel involvement.

Score 1 = single vessel involvement.

Score 2 = double vessel involvement.

Score 3 = triple vessel involvement.

\section{B. Friesinger score: ${ }^{6}$}

The Friesinger index is a score ranges from 0 to 15 . Each of the three main coronary arteries was scored separately from 0 to 5 . 
Score 0 : No arteriographic abnormality

Score 1: Trivial irregularities (lesion from 1-29\%)

Score 2 : Localized $30-68 \%$ luminal narrowing

Score 3 : Multiple $30-68 \%$ luminal narrowing of same vessel

Score 4 : 69-100\% luminal narrowing without 100\% occlusion of proximal segments

Score 5 : Total obstruction of a proximal segment of a vessel.

\section{The Leaman score: ${ }^{7}$}

A coronary scoring system to determine the severity of the underlying CAD. The 'Leaman score' is based on the severity of luminal diameter narrowing and weighted according to the usual blood flow to the left ventricle in each vessel or vessel segment.

\section{Statistical Methods:}

Data were collected by using a pre designed data sheet. Data were presented as frequency and percentage for categorical variables and as mean with standard deviation for quantitative variables. Categorical variables were analyzed by chi-square test. Quantitative variables were analyzed by t-test or ANOVA. Correlations between pulse wave velocity and angiographic severity was measured by Pearson's and Spearman's correlation test. To identify independent effects of risk factors on coronary artery disease multivariate regression analysis was done. $P$ value less than 0.05 was considered as significant. Statistical analyses were performed with the SPSS (Ver. 17.0 for Windows). Chicago, IL: SPSS Inc.

\section{Results:}

This study was done with an aim to find out the association between the aortic pulse wave velocity and the angiographic severity of coronary artery disease in patients with non-ST-segment elevation myocardial infarction. On the basis of PWV, study subjects were categorized into two groups: 50 patients of NSTEMI with normal PWV ( $\leq 10 \mathrm{~m} / \mathrm{sec}$ ) were considered as group I and 50 patients of NSTEMI with increased PWV (>10 m/ $\mathrm{sec})$ were considered as group II.

Table I shows the risk factors among the studied patients. Highest percentage had history of smoking (58\%) followed by hypertension (47\%), diabetes mellitus (40\%), dyslipidaemia (33\%), family history of premature CAD $(30 \%)$. Smoking, diabetes mellitus, hypertension, dyslipidemia and family history of premature CAD were higher in group II than in group I. It was observed that all risk factors were insignificantly greater in Group II ( $p>0.05)$.

Table-I

Risk factors of the study patients $(n=100)$

\begin{tabular}{|c|c|c|c|c|c|c|c|}
\hline \multirow[t]{2}{*}{ Risk Factors } & \multicolumn{2}{|c|}{ Group I $(n=50)$} & \multicolumn{2}{|c|}{ Group II (n=50) } & \multicolumn{2}{|c|}{$\begin{array}{c}\text { Total } \\
(\mathrm{n}=100)\end{array}$} & \multirow[t]{2}{*}{$p$ value } \\
\hline & Number & $\%$ & Number & $\%$ & Number & $\%$ & \\
\hline \multicolumn{8}{|l|}{ Smoking } \\
\hline Yes & 25 & 50.0 & 34 & 68.0 & 58 & 58.0 & \multirow[t]{2}{*}{$0.07^{\mathrm{ns}}$} \\
\hline No & 25 & 50.0 & 16 & 32.0 & 42 & 42.0 & \\
\hline \multicolumn{8}{|l|}{ Hypertension } \\
\hline Yes & 20 & 40.0 & 29 & 58.0 & 47 & 47.0 & \multirow[t]{2}{*}{$0.06^{\text {ns }}$} \\
\hline No & 30 & 60.0 & 21 & 42.0 & 53 & 53.0 & \\
\hline \multicolumn{8}{|c|}{ Diabetes mellitus } \\
\hline Yes & 17 & 34.0 & 23 & 46.0 & 40 & 40.0 & \multirow[t]{2}{*}{$0.22^{\mathrm{ns}}$} \\
\hline No & 33 & 66.0 & 27 & 54.0 & 60 & 60.0 & \\
\hline \multicolumn{8}{|c|}{ Dyslipidaemia } \\
\hline Yes & 13 & 26.0 & 20 & 40.0 & 33 & 33.0 & \multirow[t]{2}{*}{$0.14^{\mathrm{ns}}$} \\
\hline No & 37 & 74.0 & 30 & 60.0 & 67 & 67.0 & \\
\hline \multicolumn{8}{|c|}{ Family $\mathrm{H} / \mathrm{O}$ of premature $\mathrm{CAD}$} \\
\hline Yes & 13 & 26.0 & 17 & 34.0 & 30 & 30.0 & \multirow[t]{2}{*}{$0.38^{\mathrm{ns}}$} \\
\hline No & 37 & 74.0 & 33 & 66.0 & 70 & 70.0 & \\
\hline
\end{tabular}

Group I: Patients with PWV $\leq 10 \mathrm{~m} / \mathrm{sec}$

Group II: Patients with PWV > $10 \mathrm{~m} / \mathrm{sec}$

$p$ value reached from Chi Square test

$s=$ Significant $(p<0.05), n s=$ Not significant $(p>0.05)$ 
Table-II

Distribution of the study patients according to vessel score $(n=100)$

\begin{tabular}{lcccccc}
\hline Vessel Score & \multicolumn{2}{c}{ Group I $(\mathrm{n}=50)$} & & \multicolumn{2}{c}{ Group II $(\mathrm{n}=50)$} & \multirow{2}{c}{$\mathrm{p}$ value } \\
\cline { 2 - 4 } \cline { 5 - 6 } & Number & $\%$ & & Number & $\%$ & $0.04^{\mathrm{s}}$ \\
\hline Score -0 & 10 & 20.0 & 3 & 6.0 & $0.02^{\mathrm{s}}$ \\
Score -1 & 24 & 48.0 & & 13 & 26.0 & $0.04^{\mathrm{s}}$ \\
Score -2 & 11 & 22.0 & 17 & 34.0 & $0.003^{\mathrm{s}}$ \\
Score -3 & 5 & 10.0 & 17 & 34.0 & \\
\hline
\end{tabular}

Group I: Patients with PWV $\leq 10 \mathrm{~m} / \mathrm{sec}$

Group II: Patients with PWV $>10 \mathrm{~m} / \mathrm{sec}$

$\mathrm{s}=$ Significant

$p$ value reached from Chi Square test.

Table II shows the vessel score of the study patients. It was found that among group II, highest percentage was of 3 and 2 vessel score (34\%) followed by 1 vessel score $26 \%$. Six percent patients had 0 vessel score. On the contrary, among group I, highest percentage was of 1 vessel score (48\%). $22 \%$ and $10 \%$ belonged to 2 and 3 vessel score and $20 \%$ patient had 0 vessel score. No vessel involvement and single vessel involvement was found significantly higher in group I ( $p=0.04$ and $p=0.02)$, double and triple vessel involvement was also found significantly higher in group II $(p=0.04$ and $p=0.003)$

Table III shows the mean PWV $(\mathrm{m} / \mathrm{sec})$ of study patients according to the number of vessels involvement. The mean PWV of subjects with normal angiographic findings was $8.21 \pm 1.8 \mathrm{~m} / \mathrm{sec}$. The mean PWV of single, double and triple vessel disease were $9.88 \pm 2.02,11.95 \pm 2.61$ and $14.37 \pm 2.96(\mathrm{~m} / \mathrm{sec})$ respectively. The PWV increased in proportion with the number of vessel involved and the differences were statistically significant $(p=0.001)$.
Table IV shows that normal Friesinger score (0) was found in $3(6 \%)$ patients in group II and $10(20 \%)$ patients in group I. Low Friesinger score (1-4) was found in $4(8 \%)$ and $19(38 \%)$ patients in group II and group I respectively. It was observed that normal and low Friesinger score was greater in group I with statistically significant difference $(p=0.03$ and $p=0.001$ respectively). Intermediate (5-10) and high Friesinger score (11-15) was found in $25(50 \%)$ and $18(36 \%)$ patients in group II and $17(34 \%)$ and $4(8 \%)$ patients in group I. Intermediate and high Friesinger score was significantly higher in group $\|(p=0.04$ and $p=0.002$ respectively).

Table $\mathrm{V}$ shows the mean level of PWV $(\mathrm{m} / \mathrm{sec})$ was observed $12.6 \pm 3.1$ and $9.5 \pm 2.2$ in significant and insignificant $C A D$ respectively. The difference of mean PWV between the insignificant and significant CAD groups was statistically significant $(p=0.001)$.

Table-III

Association between PWV and number of vessels involved $(n=100)$

\begin{tabular}{lccc}
\hline No. of vessel involved & \multicolumn{2}{c}{$P W V(\mathrm{~m} / \mathrm{sec})$} & $\mathrm{p}$ value \\
\cline { 2 - 3 } & Mean & SD & \\
\hline No vessel involvement $(n=13)$ & 8.21 & 1.86 & $0.001^{\mathrm{s}}$ \\
Single $(n=39)$ & 9.88 & 2.02 & \\
& & & \\
Double $(n=48)$ & 11.95 & 2.61 & \\
Triple $(n=54)$ & 14.37 & 2.96 & \\
\hline
\end{tabular}

$p$ value reached from ANOVA test

$\mathrm{s}=$ Significant 
Table-IV

Distribution of the study patients according to Friesinger score $(n=100)$

\begin{tabular}{|c|c|c|c|c|c|}
\hline \multirow[t]{2}{*}{ Friesinger Score } & \multicolumn{2}{|c|}{ Group I $(n=50)$} & \multicolumn{2}{|c|}{ Group II (n=50) } & \multirow[t]{2}{*}{$p$ value } \\
\hline & Number & $\%$ & Number & $\%$ & \\
\hline Normal (0) & 10 & 20.0 & 3 & 6.0 & $0.03^{s}$ \\
\hline $\operatorname{Low}(1-4)$ & 19 & 38.0 & 4 & 8.0 & $0.001^{\mathrm{s}}$ \\
\hline Intermediate $(5-10)$ & 17 & 34.0 & 25 & 50.0 & $0.04^{\mathrm{s}}$ \\
\hline High $(11-15)$ & 4 & 8.0 & 18 & 36.0 & $0.002^{s}$ \\
\hline
\end{tabular}

Group I: Patients with PWV $\leq 10 \mathrm{~m} / \mathrm{sec}$

Group II: Patients with PWV > $10 \mathrm{~m} / \mathrm{sec}$

$\mathrm{s}=$ Significant; ns=Not significant

$p$ value reached from Chi Square test and Fisher's exact test.

Table-V

Mean status of PWV of the study patients according to significant coronary artery disease defined by Friesinger index $(n=100)$

\begin{tabular}{llll}
\hline PWV m/sec & $\begin{array}{l}\text { Insignificant CAD }(n=46) \\
\text { Significant CAD }(n=54)\end{array}$ & $\begin{array}{l}\text { (Friesinger score 0-4) } \\
\text { (Friesinger score e"5) }\end{array}$ & $p$ value \\
\hline Mean \pm SD & $9.5 \pm 2.2 \mathrm{~m} / \mathrm{sec}$ & $12.6 \pm 3.1 \mathrm{~m} / \mathrm{sec}$ & $0.001^{\mathrm{s}}$ \\
\hline
\end{tabular}

$\mathrm{s}=$ Significant

$p$ value reached from unpaired t test.

The figure shows that there was a positive correlation between PWV and coronary artery disease severity in terms of vessel score $(r=0.65)$. It was observed that the Spearman's rank correlation was statistically significant $(p=0.01)$ by correlation test.

The figure shows that there was a positive correlation between PWV and coronary artery disease severity in terms of Friesinger score $(r=0.61)$. It was observed that

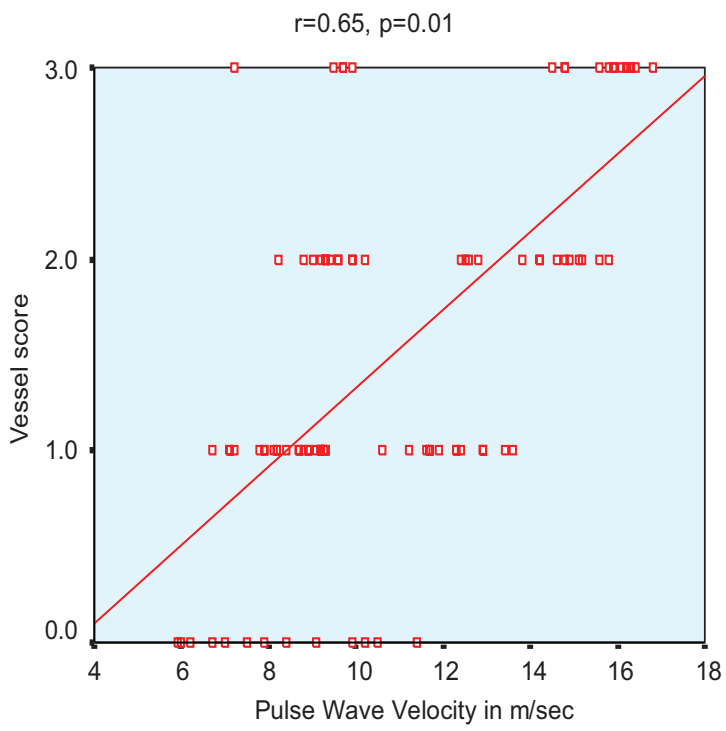

Fig.-1: Correlation between PWV and vessel score the Spearman's rank correlation was statistically significant $(p=0.01)$ by correlation test.

The figure shows that there was a positive correlation between PWV and coronary artery disease severity in terms of Leaman score $(r=0.36)$. It was observed that the Pearson's correlation was statistically significant $(p=0.01)$ by correlation test.

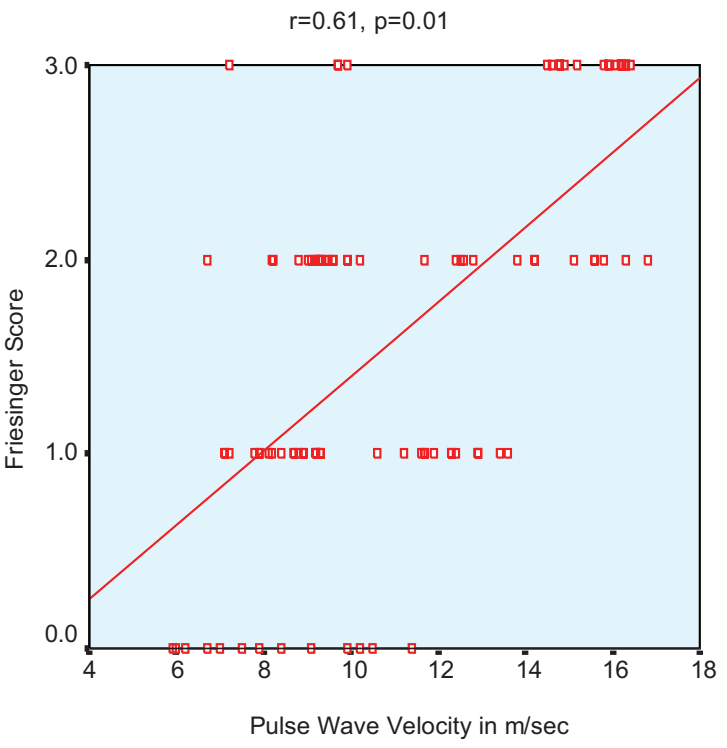

Fig.-2: Correlation between PWV and Friesinger score 


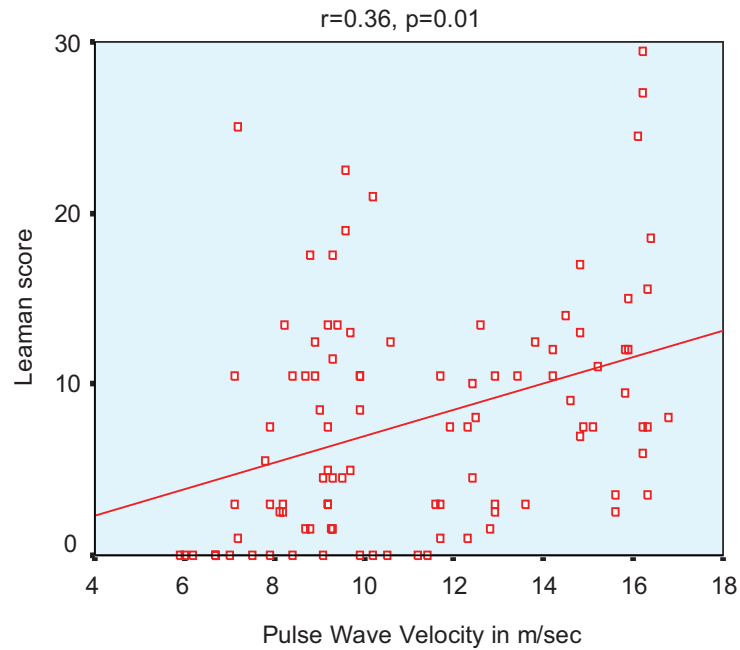

Fig.-3: Correlation between PWV and Leaman score
Table VI demonstrates the binary logistic regression analysis of odds ratio (OR) for characteristics of the subjects likely to cause coronary artery disease. The variables revealed to be significantly associated with severe CAD by univariate analysis. Of the 6 variables diabetes mellitus, hypertension and PWV were found to be the independently significant predictors of severe CAD with odds ratios being 2.12, 2.53 and 1.48 respectively.

Table VII demonstrates the binary logistic regression analysis of odds ratio (OR) for characteristics of the subjects likely to cause coronary artery disease severity. The variables revealed to be significantly associated with severe CAD by multivariate analysis were entered into the model directly. Of the 6 variables diabetes mellitus, hypertension and PWV were found to be the independently significant predictors of severe CAD with odds ratios being $2.10,2.19$ and 1.47 respectively.

Table-VI

Univariate analysis of determinants of CAD (by Friesinger score).

\begin{tabular}{lccccc}
\hline Variables of interest & $\mathrm{B}$ & $\mathrm{S} . \mathrm{E}$. & $\mathrm{p}$ value & $\mathrm{OR}$ & $95 \% \mathrm{Cl}$ \\
\hline Smoking & 0.278 & 0.407 & 0.49 & 1.32 & $0.595-2.930$ \\
Diabetes mellitus & 0.753 & 0.421 & $0.03^{\mathrm{s}}$ & 2.12 & $1.061-4.849$ \\
Hypertension & 0.927 & 0.414 & $0.02^{\mathrm{s}}$ & 2.53 & $1.122-5.691$ \\
$\quad$ Dyslipidemia & 0.223 & 0.391 & 0.23 & 0.60 & $0.258-1.386$ \\
Family history of CAD & 0.230 & 0.396 & 0.60 & 0.80 & $0.337-1.873$ \\
PWV & 0.389 & 0.087 & $0.001^{\mathrm{s}}$ & 1.48 & $1.244-1.750$ \\
\hline
\end{tabular}

Dependent variable: CAD;

Independent variables: smoking, diabetes mellitus, hypertension, dyslipidemia, family history of CAD and PWV $\mathrm{s}=$ Significant

Table-VII

Multivariate logistic regression of determinants of CAD (by Friesinger score).

\begin{tabular}{lccccc}
\hline Variables of interest & $\mathrm{B}$ & $\mathrm{S} . \mathrm{E}$. & $\mathrm{p}$ value & OR & $95 \% \mathrm{Cl}$ \\
\hline Smoking & 0.260 & 0.399 & 0.92 & 0.95 & $0.362-2.501$ \\
Diabetes mellitus & 0.658 & 0.401 & $0.04^{\mathrm{s}}$ & 2.10 & $1.042-4.242$ \\
Hypertension & 0.785 & 0.507 & $0.03^{\mathrm{s}}$ & 2.19 & $1.031-5.923$ \\
$\quad$ Dyslipidemia & 0.211 & 0.291 & 0.25 & 0.58 & $0.075-0.830$ \\
Family history of CAD & 0.241 & 0.399 & 0.62 & 0.77 & $0.264-1.543$ \\
PWV & 0.388 & 0.097 & $0.001^{\mathrm{s}}$ & 1.47 & $1.219-1.781$ \\
\hline
\end{tabular}

Dependent variable: CAD;

Independent variables: smoking, diabetes mellitus, hypertension, dyslipidemia, family history of CAD and PWV $\mathrm{s}=$ Significant 


\section{Discussion:}

This study was done with an aim to find out the association between the aortic pulse wave velocity and the angiographic severity of coronary artery disease in patients with non-ST-segment elevation myocardial infarction. A total of 100 patients with NSTEMI who agreed to undergo coronary angiography were included in the study. Coronary angiogram was done during index hospital admission. On the basis of pulse wave velocity (PWV), study subjects were categorized into two groups: 50 patients of NSTEMI with normal PWV (d"10 m/sec) were considered as group I and 50 patients of NSTEMI with increased PWV $(>10 \mathrm{~m} / \mathrm{sec})$ were considered as group II.

The distribution of common risk factors for coronary artery disease in the present study revealed that smoking habit was found in $58(58 \%)$ followed by hypertension 47 (47\%), diabetes mellitus $40(40 \%)$, dyslipidaemia 33 $(33 \%)$, family history of premature CAD $30(30 \%)$. It was observed that all risk factors were insignificantly greater in Group II than in Group I ( $p>0.05)$. Khan, et al. ${ }^{8}$ found that smoking was the highest prevalent risk factor. This distribution of risk factors in study population is consistent with those found by Matsushima, et al. ${ }^{9}$ and Wang, et al. ${ }^{10}$. However different studies carried out abroad demonstrated different patterns. This may be due to ethnic and cultural differences among the study populations. Mulders, et al. ${ }^{11}$ found that first degree relatives with patients with premature coronary artery disease had higher PWV compared with unrelated controls. Similar to these findings, proportion of patients with positive family history of CAD was higher in group II of the present study.

In this study it was found that among group II, highest percentage was of 3 vessel score and 2 vessel score (34\%) followed by 1 vessel score (26\%). Six percent patients had 0 vessel score. On the contrary among group I, highest percentage was of 1 vessel score (48\%). $22 \%$ and $10 \%$ belonged to 2 and 3 vessel score and 20\% patient had 0 vessel score. 0 vessel and 1 vessel involvement was found significantly higher in group I $(p=0.04$ and $p=0.02)$, double and triple vessel involvement was also found significantly higher in group II ( $p=0.04$ and $p=0.003$ respectively).

The mean PWV of subjects with normal angiographic findings was $8.21 \pm 1.8 \mathrm{~m} / \mathrm{sec}$. The mean PWV of single, double and triple vessel disease were 9.88 $\pm 2.02,11.95 \pm$ 2.61 and $14.37 \pm 2.96(\mathrm{~m} / \mathrm{sec})$ respectively. The PWV increased in proportion with the number of vessels involved and the differences were statistically significant $(p=0.001)$. Alarhabi, et al. ${ }^{12}$ found that the mean PWV in the group with normal angiographic results was $8.14 \pm 1.25 \mathrm{~m} / \mathrm{sec}$ and in patients with single-vessel disease it was $11.13 \pm 0.91 \mathrm{~m} / \mathrm{sec}$. In those with double vessel disease mean PWV was $15.22 \pm 1.11 \mathrm{~m} / \mathrm{sec}$, and in the multiple-vessel disease group it was $19.30 \pm 2.05$ $\mathrm{mD}$ sec. There was statistically significant difference of PWV between the groups involving coronary arteries $(P<.001)$. So, these findings of the present study are similar to the findings of the study done by Alarhabi, et al. ${ }^{12}$

Study conducted by Fukuda, et al. ${ }^{13}$ found that patients with 3 vessel disease group had significantly higher PWV than the patients with normal coronary artery group $(p<0.01)$, the 1 vessel disease group $(p<0.01)$ and the 2 vessel disease group $(p<0.05)$. Furthermore, PWV was significantly correlated with the number of diseased vessel ( normal coronary artery group vs. 1 vessel disease group vs. 2 vessel disease group vs. 3 vessel disease group : $14.81 \mathrm{~m} / \mathrm{sec}$ vs. $15.05 \mathrm{~m} / \mathrm{sec}$ vs. $15.7 \mathrm{~m} / \mathrm{sec}$ vs. $17.27 \mathrm{~m} / \mathrm{sec}$ ). PWV values of Fukuda, et al. ${ }^{13}$ differ from the values of the present study as because ankle-brachial PWV was measured instead of carotid femoral PWV in the former study.

Ouchi, et al. ${ }^{14}$ found PWV was significantly greater in triple vessel disease group $(14.06 \pm .88 \mathrm{~m} / \mathrm{sec})$ than in normal group $(8.9 \pm 1.2 \mathrm{~m} / \mathrm{sec})$. So, in the above mentioned studies it was found that the PWV increased with increase in number of vessels involved which is similar to this present study.

In the present study, analysis of Friesinger score revealed that normal Friesinger score (0) was found in $3(6 \%)$ patients in group II and $10(20 \%)$ patients in group I. Low Friesinger score (1-4) was found in $4(8 \%)$ and $19(38 \%)$ patients in group II and group I respectively. Intermediate Friesinger score (5-10) was found in $25(50 \%)$ patients in group II and in 17 (34\%) patients in group I. High Friesinger score (11-15) was found in 18 (36\%) patients in group II and $4(8 \%)$ patients in group I. Normal and low Friesinger score were significantly higher in Group I $(p=0.03$ and $p=0.001$ respectively). Intermediate and high Friesinger score were significantly higher in group II. ( $p=0.04$ and $p=0.002$ respectively).

Friesinger score 0-4 was defined as insignificant CAD whereas Friesinger score $\geq 5$ was defined as significant CAD. The mean PWV was observed $12.6 \pm 3.1 \mathrm{~m} / \mathrm{sec}$ and $9.5 \pm 2.2 \mathrm{~m} / \mathrm{sec}$ in significant and insignificant CAD respectively. The difference of mean PWV between the significant and insignificant CAD groups was statistically significant $(p=0.001)$, hence, PWV was significantly higher 
in patients with significant CAD. Lee, et al. ${ }^{15}$ found that the carotid radial PWV was higher in the complex lesion than in the simple lesion $(9.55 \pm 1.5 \mathrm{~m} / \mathrm{sec}$ vs. $8.99 \pm 1.5$ $\mathrm{m} / \mathrm{sec}$ respectively, $\mathrm{p}<.05$ ). This finding is consistent to our study but differ in value as because Yamashina, et al. ${ }^{16}$ noted that carotid femoral PWV is greater than carotid radial PWV but smaller than brachial ankle PWV.

In his study Covic, et al. ${ }^{17}$ found that the patients with normal angiogram had significantly less arterial stiffness (as reflected by lower aortic PWV velocity, $8.2 \pm 1.53 \mathrm{~m} /$ $\mathrm{sec}$ ) compared with the patients with obstructive coronary disease at angiography $(13.21 \pm 1.15 \mathrm{~m} / \mathrm{sec})$. Moreover as more coronary vessels were affected, PWV increased proportionately. There was a statistically significant linear relationship between the atherosclerotic burden and measures of arterial stiffness and the result is closely related to the present study.

In this study there was a positive correlation between aortic PWV and coronary artery disease severity in terms of vessel score, Friesinger score and Leaman score $(r=0.65, r=0.61$ and $r=0.36$ respectively, $p=0.01)$.

Hope, et al. ${ }^{18}$ found in his study that he stenosis score were independently associated with aortic PWV $(r=0.58$, $p<.001$ ) whereas, Lee, et al. ${ }^{15}$ found that the modified stenosis score had a positive correlation with PWV $(r=0.55, p<0.001)$. These findings are consistent with those of the present study.

The binary logistic regression analysis of odds ratio (OR) for characteristics of the subjects likely to cause coronary artery disease, the variables revealed to be significantly associated with severe CAD by univariate analysis. Of the 6 variables diabetes mellitus, hypertension and PWV were found to be the independently significant predictors of severe CAD with ORs being 2.12, 2.53 and 1.48 respectively.

The odds ratio of aortic PWV for CAD was 1.38 , found in the study done by Laurent, et al. ${ }^{19}$, which is similar to our study. Blacher, et al. ${ }^{5}$ found that the odds ratio of PWV for MI was 3.5 which differ from this study because they determined the odds ratio considering the value of PWV $>13.5 \mathrm{~m} / \mathrm{sec}$ as an independent variable.

The binary logistic regression analysis of odds ratio (OR) for characteristics of the subjects likely to cause coronary artery disease severity, the variables revealed to be significantly associated with severe CAD by multivariate analysis were entered into the model directly. Of the 6 variables diabetes mellitus, hypertension and PWV were found to be the independently significant predictors of severe CAD with odds ratios being 2.10, 2.19 and 1.47 respectively.

In their study, Kullo, et al. ${ }^{20}$ found hypertension and aortic PWV to be independently associated with CAD, whereas, Alarhabi, et al. ${ }^{10}$ found dyslipidemia and PWV as independent predictor for CAD. In the more recently published study by Wang, et al. ${ }^{8}$ diabetes mellitus and aortic PWV were independent predictors for CAD. So, the findings of the present study correlate well with those studies done abroad.

\section{Conclusion:}

In conclusion, from this study it may be stated that arterial stiffness, as measured by the aortic pulse wave velocity, is an independent predictor of the presence and extent of coronary artery disease. This noninvasive evaluation method may be used as a useful marker of end organ damage in arterial system and help to identify patients at high risk for coronary artery disease. Early screening may help in early diagnosis and treatment of underlying vascular conditions before development into more serious illness. Moreover, measurements of aortic pulse wave velocity in non-ST-segment elevation myocardial infarction can detect high risk patients requiring an early invasive strategy over a delayed invasive strategy.

\section{Study limitation:}

This was a single center study and purposive sampling was done instead of random sampling method. Study was conducted only with NSTEMI patients, so the findings may not be applicable to the general population. Angiographic severity of coronary artery disease was evaluated by visual estimation, so chance of interobserver and intraobserver variation remained.

\section{References:}

1. Oliver JJ, Webb DJ. Noninvasive assessment of arterial stiffness and risk of atherosclerotic events. Arterioscler Thromb Vasc Biol 2003;23:554-566.

2. Hayashi T, Nakayama Y, Tsumurak M, Yoshimaru $\mathrm{K}$, Ueda $\mathrm{H}$. Reflection in the arterial system and the risk of coronary heart disease. Am J Hypertens 2002;15:415-419.

3. Madhavan S, Ooi WL, Cohen H, Alderman MH. Relation of pulse pressure and blood pressure reduction to the incidence of myocardial infarction. Hypertension 1994;23: 395-401.

4. Laurent S, Cockcroft J, Van Bortel L, Boutouyrie P, Giannattasio C, Hayoz D, et al. Expert consensus document on arterial stiffness: methodological issues and clinical applications. Eur Heart $J$ 2006;27:2588-2605. 
5. Blacher J, Asmar R, Djane S, London GM, Safar ME. Aortic pulse wave velocity as a marker of cardiovascular risk in hypertensive patients. Hypertension 1999;33:1111-1117.

6. Ringqvist I, Fisher LD, Mock M, Davis KB, Wedel H, Chaitman BR, et al. Prognostic value of Angiographic Indices of coronary artery disease from the Coronary Artery Surgery Study (CASS). $J$ Clin Invest 1983;71:1854-66.

7. Leaman DM, Brower RW, Meester GT. Coronary artery atherosclerosis: severity of the disease, severity of angina pectoris and compromised left ventricular function. Circulation 1981;63:285-99.

8. Khan AR, Islam AEM, Ali M, Majumder AAS, Khan A. Study of risk factors and coronary angiographic pattern in younger patients with acute coronary syndrome. Bangladesh Heart J 2004;19:109-119.

9. Matsushima $\mathrm{Y}$, Kawano H, Koide $\mathrm{Y}, \mathrm{Baba} \mathrm{T}$, Toda $\mathrm{G}$, Seto S, et al. Relationship of carotid intima-media thickness, pulse wave velocity, and ankle brachial index to the severity of coronary artery atherosclerosis. Clin Cardiol 2004;27:629-634.

10. Wang D, Tang Q, Shin SH, Hua Q. Prediction of coronary artery diseases in pulse wave velocity and retinal artery lesions. Tohoku J. Exp. Med 2011;225:17-22.

11. Mulders TA, van den Bogaard B, Bakker A, Trip MD, Stroes ES, van den Born BJ, et al. Arterial stiffness is increased in families with premature coronary artery disease. Heart 2012;98:490-494.

12. Alarhabi AY, Mohamed MS, Ibrahim S, Hun TM, Musa $\mathrm{KI}$, Yusof Z. Pulse wave velocity as a marker of severity of coronary artery disease. J Clin Hypertens (Greenwich) 2009;11:17-21.

13. Fukuda D, Yoshiyama M, Shimada K, Yamashita $\mathrm{H}$, Ehara S, Nakamura $\mathrm{Y}$, et al. Relation between aortic stiffness and coronary flow reserve in patients with coronary artery disease. Heart 2006;92: 759-762.

14. Ouchi Y, Terashita K, Nakamura T, Yamaoki $\mathrm{K}$, Yazaki Y, Toda E, et al. Aortic pulse wave velocity in patients with coronary atherosclerosis-a comparison with coronary angiographic findings. Nihon Ronen Igakkai Zasshi 1991;28:40-45.

15. Lee YS, Kim KS, Wang R, Nam CW, Han SW, Hur $\mathrm{SH}$, et al. Clinical implication of carotid-radial pulse wave velocity for patients with coronary artery disease. Korean Circulation J 2006;36:565-572.

16. Yamashina A, Tomiyama $\mathrm{H}$, Takeda K, Tsuda $\mathrm{H}$, Arai T, Hirose K, et al. Validity, reproducibility, and clinical significance of noninvasive brachial-ankle pulse wave velocity measurement. Hypertens Res 2002;25:359-364.

17. Covic A, Haydar AA, Bhamra-Ariza P, GusbethTatomir P, Goldsmith DJ. Aortic pulse wave velocity and arterial wave reflections predict the extent and severity of coronary artery disease in chronic kidney disease patients. J Nephrol 2005;18:388-396.

18. Hope SA, Antonis P, Adam D, Cameron JD, Meredith IT. Arterial pulse wave velocity but not augmentation index is associated with coronary artery disease extent and severity: implications for arterial transfer function applicability. J Hypertens 2007;25:2105-2109.

19. Laurent S, Boutouyrie P, Asmar R, Gautier I, Laloux $B$, Guize L, et al. Aortic stiffness is an independent predictor of all-cause and cardiovascular mortality in hypertensive patients. Hypertension 2001;37:1236-1241.

20. Kullo IJ, Bielak LF, Turner ST, Sheedy PF 2nd, Peyser PA. Aortic pulse wave velocity is associated with the presence and quantity of coronary artery calcium: a community-based study. Hypertension 2006;47:174-179. 